\title{
Hydrological Response of East China to the Variation of East Asian Summer Monsoon
}

\author{
Fuxing Li, ${ }^{1,2}$ Dong Chen, ${ }^{1}$ Qiuhong Tang, ${ }^{1}$ Wenhong Li, $^{3}$ and Xuejun Zhang ${ }^{1,2}$ \\ ${ }^{1}$ Key Laboratory of Water Cycle and Related Land Surface Processes, Institute of Geographic Sciences and \\ Natural Resource Research, Chinese Academy of Sciences, Beijing, China \\ ${ }^{2}$ University of Chinese Academy of Sciences, Beijing, China \\ ${ }^{3}$ Earth and Ocean Sciences, Nicholas School of the Environment, Duke University, Durham, NC, USA \\ Correspondence should be addressed to Dong Chen; dchen@igsnrr.ac.cn
}

Received 16 May 2016; Revised 29 July 2016; Accepted 10 August 2016

Academic Editor: Min-Hui Lo

Copyright (C) 2016 Fuxing Li et al. This is an open access article distributed under the Creative Commons Attribution License, which permits unrestricted use, distribution, and reproduction in any medium, provided the original work is properly cited.

\begin{abstract}
The sensitivity of hydrologic variables in East China, that is, runoff, precipitation, evapotranspiration, and soil moisture to the fluctuation of East Asian summer monsoon (EASM), is evaluated by the Mann-Kendall correlation analysis on a spatial resolution of $1 / 4^{\circ}$ in the period of 1952-2012. The results indicate remarkable spatial disparities in the correlation between the hydrologic variables and EASM. The regions in East China susceptible to hydrological change due to EASM fluctuation are identified. When the standardized anomaly of intensity index of EASM (EASMI) is above 1.00, the runoff of Haihe basin has increased by $49 \%$ on average, especially in the suburb of Beijing and Hebei province where the runoff has increased up to 105\%. In contrast, the runoff in the basins of Haihe and Yellow River has decreased by about 27\% and 17\%, respectively, when the standardized anomaly of EASMI is below -1.00 , which has brought severe drought to the areas since mid-1970s. The study can be beneficial for national or watershed agencies developing adaptive water management strategies in the face of global climate change.
\end{abstract}

\section{Introduction}

Typical continental monsoon climate prevails across large territory of China. Among others, East Asian summer monsoon (EASM) has significant impacts on the amount and distribution of summer rainfall in East China and thus influences the spatial-temporal variations of water resources in this region [1-4]. Much of the previous research has focused on the relationship between EASM and precipitation as well as temperature in East China [5-18]. Among others, Yang et al. [19] and Huang et al. [20] find that both the severe floods in the watersheds of Yangtze River and Huaihe and the prolonged droughts in North China since the late 1970s are attributed to the interannual and interdecadal variations of the EASM. Guo et al. [21] and Zhu et al. [6] show that there is a distinct 80 -year oscillation of summer rainfall in East China, and heavy summer rainfall over North China and serious droughts over the middle and lower reaches of Yangtze River could be found during strong EASM periods. Similarly, Zhao and Zhou [22] also discover that a heavy rainfall over the Yangtze River watershed usually is accompanied with a weak EASM, which may strengthen the convergence and ascending motions of water vapor along the front of Plum Rains. Besides the researches on the relationship between the EASM and precipitation, Lin et al. [23] find a positive correlation between the East Asian summer monsoon index (EASMI) and the index of summer surface air temperature (SAT) in eastern China during 2/3 of the period of 1880-2004. Furthermore, Liu and Wang [10] recognize the middle reaches of Yangtze River, the most susceptible to the change of SAT due to EASM fluctuation. The increase of SAT in summer enhances the ocean-land thermal contrast [24], which in turn increases the intensity of EASM [25]. In conclusion, previous studies have indicated an evident relationship between EASM and meteorological variables (e.g., precipitation and air temperature) in East China.

The impact of EASM on streamflow of East China has also been evaluated in previous researches. Comparing to the meteorological data, relatively long-term flow discharge has 
TABLE 1: Characteristic of the eight watersheds in the monsoon region of east China.

\begin{tabular}{|c|c|c|c|c|}
\hline \multirow{2}{*}{ Basins } & \multicolumn{2}{|c|}{ Drainage area } & \multirow{2}{*}{$\begin{array}{l}\text { Average elevation } \\
\text { (m) }\end{array}$} & \multirow{2}{*}{$\begin{array}{c}\text { Annual rainfall } \\
(\mathrm{mm})\end{array}$} \\
\hline & $\left(10^{4} \mathrm{~km}^{2}\right)$ & $\%$ of total area of East China & & \\
\hline The yellow River & 75.24 & 14.80 & 1918.51 & 459.60 \\
\hline The Yangtze River & 180.00 & 35.54 & 1606.14 & 1126.70 \\
\hline The Liaohe River & 29.69 & 5.86 & 423.62 & 638.20 \\
\hline The Pearl River & 45.36 & 8.96 & 537.94 & 1579.00 \\
\hline The Huaihe River & 27.47 & 5.42 & 86.36 & 814.80 \\
\hline The Haihe River & 31.82 & 6.28 & 576.85 & 548.00 \\
\hline The Songhua River & 95.22 & 18.80 & 453.31 & 534.90 \\
\hline The Southeast Rivers & 21.59 & 4.26 & 478.86 & 1526.60 \\
\hline
\end{tabular}

been recorded for a few large rivers in China. For example, Zhang et al. [26] find that the annual maximum discharge of the upper and lower Yangtze River, based on a 135-year record, is mainly influenced by Indian summer monsoon and EASM. Xu and Ma [27] and Xu [28] find a strong relationship between the 5-year moving averages of EASMI and discharge difference between Hekouzhen and Longmen gauges of the Yellow River in the period of 1919-2000. They argue that, during weak EASM events, less water vapor transport by the EASM decreases runoff at watershed scales. Wei et al. [29] examine the spatial variation of discharge oscillations of the Yangtze River and confirmed its strong correlation with EASM and El Nino Southern Oscillation (ENSO). All of these studies indicated a significant impact of EASM on the streamflow over East China.

Compared with numerous efforts directed at understanding the relationship between EASM and hydrometeorological variables (e.g., precipitation, air temperature), less researches have been done on the correlation between EASM and hydrogeological variables (e.g., soil moisture, runoff). As an important parameter denoting land surface condition, soil moisture within the depths of root systems is a critical factor that dominates crop yields from the perspective of agriculture [30]. Besides, soil moisture anomaly could modify the atmosphere circulation in seasonal to interannual time scales [31]. On the other hand, although rainfall and runoff are causally correlated in general, similar rainfall could generate distinct runoffs upon different land surfaces, especially for arid or semiarid lands. Runoff is an easily-accessible water resource and usually much more sensitive to climate change than precipitation does in East China, as discussed in the following sections. Besides, flow discharge recorded in hydrologic stations in large rivers such as the Yellow River or Yangtze River represents an average on a large spatial scale. Xu [28] found that EASM explains $72 \%$ variability in discharge difference between two consecutive gauges, Hekouzhen and Longmen, in the middle Yellow River. However, the drainage area between the two gauges is as large as $113,700 \mathrm{~km}^{2}$ [28]; the above conclusion can hardly be applied to smaller spatial scales (e.g., croplands in the region) due to spatial variation in the Runoff-EASM relationship. The above concerns motivate the present study, which evaluates the response of runoff and soil moisture as well as precipitation and evapotranspiration (ET) to the variation of EASM in the $1 / 4^{\circ}$ spatial resolution.

During the past decades, East China has become one of the most rapidly developing regions in the world. Unfortunately, northern portion of the region has suffered from a prolonged drought and thus severe shortage of water resources since the 1970s due to weak EASM. There is a pressing need for hydrologists to identify the "critical zones" in which the local water resources are most susceptible to EASM fluctuation and estimate the variance amplitude of the water resources. The study aims at helping national or watershed agencies to develop adaptive water management strategies under the global climate change.

\section{Study Area}

The study area is the monsoon region in East China including eight watersheds, that is, the Songhuajiang, Liaohe, Haihe, Yellow River, Huaihe, Yangtze River, Southeastern Rivers, and Pearl River. Table 1 summarizes the drainage area, averaged elevation, and annual rainfall amounts of the eight watersheds. The $400 \mathrm{~mm}$ iso-hyetal line is usually used to separate the monsoon region from the arid and semiarid region of Western China. Figure 1 demonstrates the locations of the eight watersheds, ground elevation, and the iso-hyetal lines of $400 \mathrm{~mm}$ and $800 \mathrm{~mm}$ as well. The basins of Yangtze River (YRB), Pear River (PRB), and Southeastern Rivers (SRB) are located in South China and the other basins are located in North China. The vegetation types in the study area vary from temperate needle broad-leaved mixed forest to subtropical and tropical evergreen broad-leaved forest from north to south, in response to local climates. Most precipitation in the study area concentrates in the summer period from June to September; however, rainfall magnitude varies tremendously in space. In contrast to the frequent floods and waterlogging in Southern China, limited water resources often restrict the development of Northern China where large portions of the population and farmlands are located. For example, the population and GDP of the basins of the Yellow River, Huaihe, and Haihe accounted for about $34.7 \%$ and $32.1 \%$ of the whole country, whereas the region is supported by only $7.5 \%$ of the nation's water resources [32]. 
TABLE 2: Calibration and verification of VIC model by comparing with monthly streamflow in the monsoon region.

\begin{tabular}{lcccccc}
\hline River basin & Calibration gauge & Calibration period & NS for calibration & Verification gauge & Verification period & NS for verification \\
\hline SRB & Changjiangtun & $1965-1984$ & 0.82 & & \\
LRB & Liaoyang & $1956-1975$ & 0.83 & & $1981-2000$ \\
HHB & Luanxian & $1958-1977$ & 0.84 & Luanxian & Guantai & $1981-2000$ \\
HHB & Guantai & $1958-1977$ & 0.77 & Tangnaihai & $1981-2000$ \\
YRB & Tangnaihai & $1958-1977$ & 0.87 & Lanzhou & $1981-2000$ \\
YRB & Lanzhou & $1958-1977$ & 0.85 & Lutai & $1981-2000$ \\
HRB & Lutai & $1958-1977$ & 0.75 & & 0.67 \\
YZB & Shigu & $1956-1975$ & 0.89 & & 0.83 \\
YZB & Wulong & $1956-1975$ & 0.82 & & \\
PRB & Boluo & $1960-1979$ & 0.82 & & \\
PRB & Wuzhou & $1960-1979$ & 0.96 & & \\
\hline
\end{tabular}

Note: YRB: Yellow River Basin; YZB: Yangtze River Basin; LRB: the Liaohe River Basin; PRB: Pearl River Basin; HRB: Huaihe River Basin; HHB: Haihe Basin; SRB: Songhua River Basin; SEB: Southeast Rivers Basin.

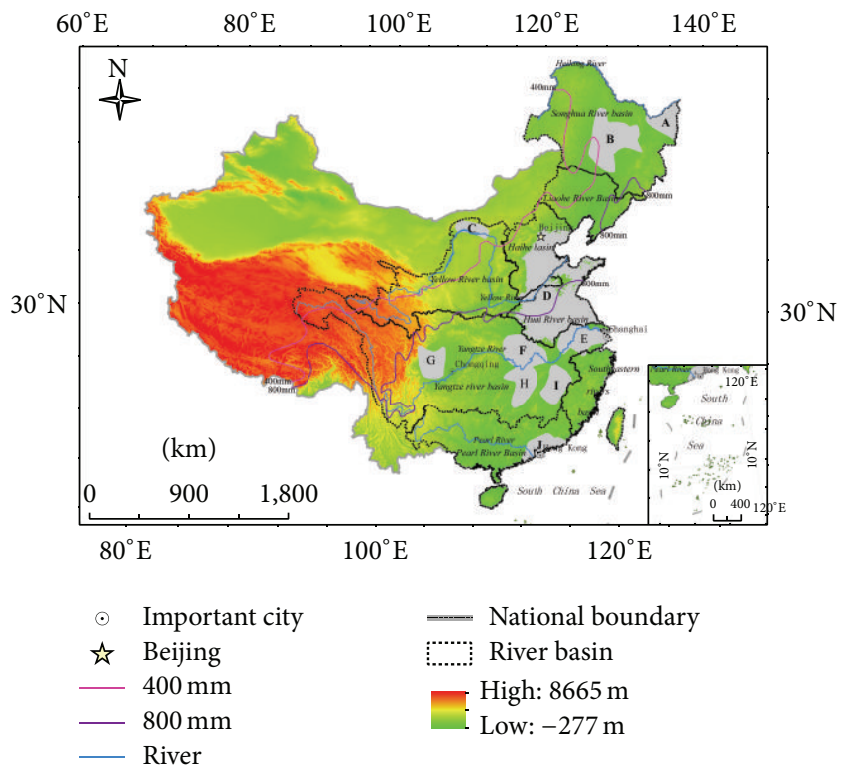

FIGURE 1: Watersheds in the monsoon region of East China. The $400 \mathrm{~mm}$ iso-hyetal line (pink curve) separates the monsoon region from the arid and semiarid region of Western China. Major croplands in China (gray areas) include A, the Sanjiang Plain, B, the Songnen Plain, C, the Hetao Plain, D, the North China Plain, E, the Taihu Plain, F, the Jianghan Plain, H, the Dongtinghu Plain, I, the Poyanghu Plain, G, the Chengdu Plain.

Figure 1 also illustrates the locations of 10 major croplands including North China Plain. Four of them are located in North China.

\section{Data Sources}

The major dataset used in the present study includes (a) hydrologic data in the study area, including precipitation, runoff, ET, and soil moisture in spatial resolution of $1 / 4^{\circ}$ for the period of 1952-2011 and (b) EASMI data for the period of 1952-2011, indicating the intensity of the East Asian summer monsoon.
3.1. Hydrological Data. The hydrological data include precipitation, runoff, ET, and soil moisture, which indicate the natural water resources in the study area.

Since observed long-term, large-scale, and high-resolution runoff and soil moisture data in the study area are absent, this study utilized the Variable Infiltration Capacity (VIC) model to simulate hydrological variables. The calculated variables, which are available at http://hydro.igsnrr.ac.cn/, were provided with 3 -hour time step and $1 / 4^{\circ}$ spatial resolution for the period of 1952-2011. For the detailed description of the computational procedure, refer to Zhang et al. [33] and a brief introduction of the model calibration/verification is given below. The VIC model is a masoscale, grid-based water and energy balance model, which has been successfully applied in many large river basins with satisfactory results [34-36]. The VIC model was set up with three soil layers with varied soil depth for each layer [33]. Surface runoff is generated in the upper two layers by a variable infiltration curve, and soil moisture is produced by accumulating water content from all the three layers.

The input data of VIC model include meteorological data (precipitation, temperature, and wind), soil data, and land cover data. The meteorological data were obtained from 756 meteorological stations of China Meteorological Administration and interpolated to $1 / 4^{\circ}$ resolution. Soil parameters are based on the 5-arc-min Food and Agriculture Organization of the United Nations dataset [37] and specified following the method of Maurer et al. [38]. The vegetation classification is derived from the University of Maryland global land cover classifications [39].

The VIC model is calibrated and validated before using for the analysis. The information of observation gauges and periods of calibration and verification are addressed in Table 2. The Nash-Sutcliffe efficiency (NS) and the relative error (RE) are employed to assess the performance of model calibration and verification:

$$
\begin{gathered}
\mathrm{NS}=1-\frac{\sum\left(Q_{i, o}-Q_{i, s}\right)^{2}}{\sum\left(Q_{i, o}-\overline{Q_{o}}\right)^{2}}, \\
\operatorname{RE}(\%)=\left[\frac{\left(\overline{Q_{s}}-\overline{Q_{o}}\right)}{\overline{Q_{o}}}\right] \times 100 \%,
\end{gathered}
$$


TABLE 3: The relative errors (\%) of ET calibration in the eight watersheds (1984-2007).

\begin{tabular}{lccc}
\hline River basin & ET_observation & ET_VIC & Relative errors (\%) \\
\hline The Yellow River & 172.32 & 207.36 & 20.34 \\
The Pearl River & 453.61 & 466.38 & 2.82 \\
The Huaihe River & 318.33 & 376.31 & 18.21 \\
The Haihe River & 245.66 & 271.03 & 10.33 \\
The Songhua River & 261.32 & 219.00 & -16.20 \\
The Liaohe River & 480.60 & 505.88 & 5.26 \\
The Yangtze River & 244.62 & 242.73 & -0.77 \\
The Southeast Rivers & 332.64 & 334.85 & 0.67 \\
\hline
\end{tabular}

where $Q_{i, o}$ and $Q_{i, s}$ are the observed and simulated data in month $i$ and $\overline{Q_{o}}$ and $\overline{Q_{s}}$ are the observed and simulated mean annual data, respectively.

Table 2 shows the parameter calibration results at 11 streamflow gauges and verification results at 5 streamflow gauges distributed in major river basins of East China. Table 2 indicates VIC simulated streamflow agrees well with the observation at those gauges. All of the NS values for calibration are above 0.75 , and NS values for verification are above 0.8 at 4 out of the 5 gauges. Table 3 compares the calculated 24-year-average ET with remote sensing data during the period of 1984-2007 [33]. The VIC simulated ET shows agreement with the observation data with the RE values below the $15.0 \%$ at 5 out of the 8 basins. The RE in the watersheds of the Yangtze River and the Pearl River show the minimum value as $-0.77 \%$ and $0.67 \%$, respectively. The maximum RE, that is, about $20 \%$, occurs in the watershed of the Yellow River which is acceptable for ET calibration.

Besides streamflow and ET, the simulated surface radiation fluxes, soil moisture, and snow cover are also verified by the datasets from the Institute of Tibetan Plateau Research at Chinese Academy of Sciences [40], Princeton University global terrestrial water budget product [41], and National Snow and Ice Data Center [42], respectively (please see details in [33]). According to [33], substantial biases exist at some gauges in western China, while the seasonal cycle of the VICderived streamflow agrees well with the observations over the eight watersheds in East China.

3.2. Index of EASM. This study adopts the EASMI defined by [43]. Many indices have been proposed to quantify the EASM $[8,44-47]$. Among these indices, the EASMI defined by [43] is based on the formative mechanism of the EASM and calculated as the difference in the monthly average air pressure in summer season (June, July, and August) at the sea level between the Asian Continent $\left(110^{\circ} \mathrm{E}\right)$ and the Pacific Ocean $\left(160^{\circ} \mathrm{E}\right)$ in the range of $10^{\circ}-50^{\circ} \mathrm{N}$. For the the procedures of EASMI calculation, refer to [43] or [28]. The data source is from NCEP/NCAR Global Reanalysis Products (http://rda.ucar.edu/datasets/ds090.0/). Figure 2 presents anomalies of EASMI and runoff in the Haihe basin

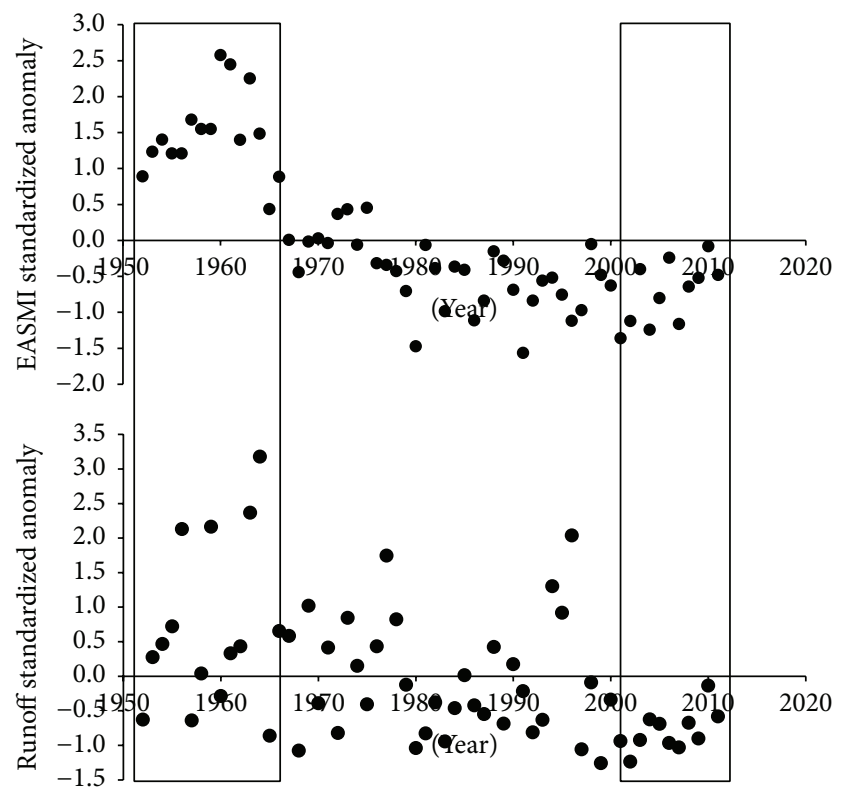

FIGURE 2: Temporal variation and categorization of standardized anomalies of EASMI and runoff in the Haihe River Basin.

over the period of 1952-2011. EASMI and runoff anomalies are calculated as follows:

$$
P=\frac{E-\bar{E}}{\sigma},
$$

where $P$ is the standardized anomaly; $E$ denotes time series; $\bar{E}$ is the mean of time series; and $\sigma$ is the standard deviation of the time series. Overall, EASMI has a distinct trend of decreasing after the 1960s. The prolonged drought in North China from the late 1970s has been attributed to the continuous decline of EASMI $[19,20]$. It is worth mentioning that the EASMI trend line tends to rise again after 2000 which has brought relatively more rainfall to North China including the extraordinary rainstorm on July 21, 2012, in Beijing City and its suburb. As the typical basin in the North China, the Haihe River Basin shows the similar variation for the runoff as well as the EASMI.

\section{Methods}

The Mann-Kendall (MK) test $[48,49]$ has been widely applied to evaluate the long-term trends of time series [5054]. Hirsch et al. successfully extended the MK function to examine the correlations between two time series $[55,56]$.

Although all the eight watersheds belong to monsoondominated region, the hydrologic variables in the study area are also impacted by many other oceanic-atmospheric factors such as ENSO $[57,58]$ and PDO $[59,60]$, which often results in statistical low correlation or even irrelevance between EASMI and the hydrologic variables when applying traditional regression equations. Besides, those impacting factors usually have various statistical distributions and interrelation between each other, which often invalidate or fail traditional regression methods. 
To solve the above problem, the nonparametric method, that is, MK test, is employed in this study, which can present the correlation between two time series effectively. Since MK test is sensitive to the autocorrelation structure in the data [61], the lag-one $(k=1)$ autocorrelation coefficients $\left(r_{1}\right)$ for EASMI and hydrometeorological variables in East China were calculated using

$$
r_{k}=\frac{(1 /(n-k)) \sum_{i=1}^{n-k}\left(x_{i}-\bar{x}\right)\left(x_{i+k}-\bar{x}\right)}{(1 / n) \sum_{i=1}^{n}\left(x_{i}-\bar{x}\right)^{2}}
$$

where $k=1 ; n=60 ; x_{i}$ denotes time series; and $\bar{x}$ is the mean of time series.

Since $r_{1}$ values for EASMI and hydrometeorological variables data are not in the scope of $(-1-1.645 \sqrt{n-2}) /(n-2) \leq$ $r_{1} \leq(-1+1.645 \sqrt{n-2}) /(n-2)$, that is, independent test at $10 \%$ significance level, the data are considered to be serially correlated and prewhitening is required before applying the Mann-Kendall test. Based on the detailed calculating course of reference [61], the time series are recalculated to get the blended series which is applied to the MK test.

In the MK test, the null hypothesis $H_{0}$ states that there is no trend for the two time series varying in pairs. Equations (4) provide the statistical test:

$$
\begin{aligned}
S & =\sum_{k=1}^{n-1} \sum_{j=k+1}^{n} S_{g n}\left(x_{j}-x_{k}\right), \\
S_{g n}\left(x_{j}-x_{k}\right) & = \begin{cases}+1 & \left(x_{j}-x_{k}\right)>0 \\
0 & \left(x_{j}-x_{k}\right)=0 \\
-1 & \left(x_{j}-x_{k}\right)<0\end{cases} \\
\tau_{a u} & =\frac{2 S}{n(n-1)}, \\
Z & = \begin{cases}\frac{S-1}{\sqrt{\operatorname{Var}(S)}} & S>0 \\
0 & S=0 \\
\frac{S+1}{\sqrt{\operatorname{Var}(S)}} & S<0 .\end{cases}
\end{aligned}
$$

In the formulas, $x_{k}$ and $x_{j}$ are the independent samples; the statistic $S$ with a mean of zero is approximately normally distributed; $\tau_{a u}$ here is the MK correlation coefficient which indicates a significant correlation between the two time series of $X$ and $Y$ if $X$ is other than time ( $\tau_{a u}$ is also called Kendall's $\tau$ coefficient identifying the significance of trend of the $Y$ if $X$ denotes time); the square root of $\operatorname{Var}(S)$ is the variance of $S$ which equals $n(n-1)(2 n+5) / 18$; $n$ is the number of samples. The null hypothesis $H_{0}$ should be rejected when $|Z| \geq Z_{1-\alpha / s}$ at the $\alpha$ level of significance. This means that the correlation between the two time series is statistically significant at the significance level of $\alpha$. The positive (+) and negative (-) signs of $Z$ denote the positive and negative correlation between the two time series, respectively. $|Z| \geq 1.28,1.64$, and 2.32 indicate the confidence level (the reciprocal of significance level $\alpha$ ) of the calculation is more than $90 \%, 95 \%$, and $99 \%$, respectively.

Student's $t$-test proposed by William Sealy Gosset [62] is also applied in Section 5.1 to examine if the mean value of selected sample is significantly different from the annual average, that is, the mean of the entire population in the period of 1952-2011. The statistical value of $t$-test is calculated as follows:

$$
t=\frac{\bar{x}-\mu_{0}}{S_{d} / \sqrt{n}}
$$

where $\bar{x}$ and $\mu_{0}$ are the means for selected sample and entire population, respectively. $S_{d}$ is the sample standard deviation and $n$ is the sample size. $S_{d} / \sqrt{n}$ denotes the standard error, and the $t$ score represents the difference between sample means divided by the standard error. Student's $t$-test is selected herein since it is capable of dealing with problems associated with small sample sizes [63], which is suitable in the present study.

\section{Results}

5.1. Regions Susceptible to EASM Fluctuation. Figure 3 identifies the regions susceptible to the changes of runoff and ET due to EASM fluctuation, respectively. The white curves in Figure 3 enclose the regions with strong correlation between the hydrologic variables and EASM above the $95 \%$ confidence level.

Strong summer monsoon carries large quantity of water vapor from the southeastern coast and goes far into inland, which brings heavy rainfall precipitation to the north and central China. Figure 3(a) shows that runoff is positively correlated to EASM in the watershed of Yellow River, the plains of North China, Songnen and Chengdu, and the peninsulas of Liaodong and Shandong. $\tau_{a u}>0.3$ with $95 \%$ confidence level occurs in the plains of North China and Chengdu as well as the middle-lower Yellow River Basin, which indicates that the runoff in these regions is more sensitive to EASM variation compared to other areas of the north China. Xu [28] also studied the impacts of EASM on the runoff in the middle Yellow river based on the runoff observations from 1919 to 2010 provided by the Yellow River Conservancy Commission, and he argued that EASM explains $72 \%$ variability in runoff in this region and reconstructed the time series of runoff from 1873 to 1918 based on the significant correlation with EASMI.

In contrast, weak summer monsoon is usually accompanied with stagnation of water-vapor transfer, which brings droughts to the north and floods to the south. Figure 3(a) also indicates a negative correlation between runoff and EASM over most areas of south China, especially in the lower Yangtze River and the upper reach of Pear River at the higher 95\% confidence level.

It is worth mentioning that Figure 3(a) indicates opposite relationships of EASM runoff in the upper and lower Yangtze River. Zhang et al. [26] state that different climatic systems, that is, the Indian summer monsoon and EASM, control the upper and lower Yangtze River, respectively. We also find a significant negative correlation between runoff and the 


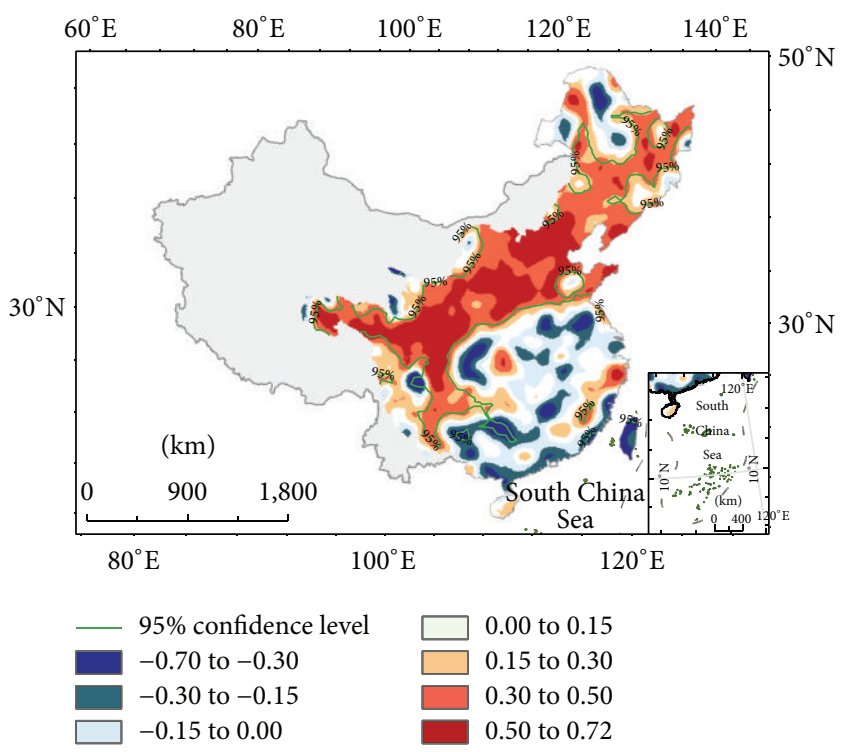

(a)

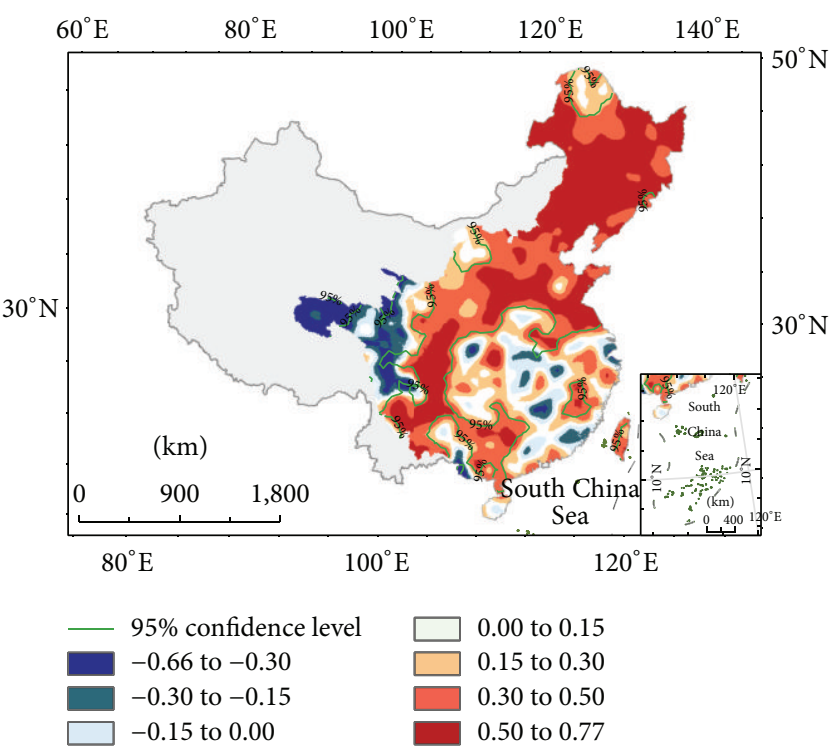

(b)

FIGURE 3: Correlations between EASM and runoff (a) as well as ET (b). The green curves draw the outline of region with $95 \%$ confidence level in MK test.

Indian summer monsoon in upper Yangtze River, especially in the basin of Jialing River (one of primary tributaries of the Yangtze River) (figures and calculation are not presented in this paper). There is a weak negative correlation between the Indian summer monsoon and runoff in the lower Yangtze River; however, the $\tau_{a u}$ calculation does not pass the $95 \%$ confidence test. Our research is consistent with the findings of Zhang et al.s [26].

As a significant water loss from drainage watersheds, ET is also an important component of the terrestrial water cycle. Figure 3(b) indicates a much larger area with significantly positive correlation between EASM and evapotranspiration including the upper Pear River Basin and coastal region in the east. Negative correlation between EASM and ET is limited to the upper and lower Yangtze River Basins and the statistics fail the $95 \%$ confidence test. The strong positive EASM-ET relationship in the study area is not surprising since increased monsoon winds accelerate evaporation rates. Besides, the formation mechanism of EASM indicates an inphase variation of EASM and the summer air temperatures, which also tends to increase the ET. The spatial patterns of correlation between EASM and precipitation as well as soil moisture are similar to those between EASM and runoff in Figure 3(a); therefore they are not demonstrated in the present study.

The values of runoff and ET are usually much higher in South China, although they show stronger correlation with EASM in North China. To ensure the sensitivity of hydrologic variables in northern and southern China to EASM change, different EASM scenarios are considered to explore the change of hydrologic variables in East China. in Basins. Besides identifying the regions susceptible to hydrologic change after EASM fluctuates, water resources agencies are also interested in quantifying the variation of hydrologic variables in terms of EASM fluctuation. In this study, we divide the standardized anomalies of EASMI in the period of 1952-2011 (see (2)) into 5 categories, that is, $-2.00 \sim$ $-1.00,-1.00 \sim-0.34,-0.34 \sim 0.34,0.34 \sim 1.00$, and $1.00 \sim 2.00$ (Figure 2). Out of the entire population of 60, the sample sizes of the 5 categories are $10,19,13,6$, and 9 , respectively. The three samples with the standardized anomalies larger than 2.00 are excluded from statistics since their sampling pool is too small for statistical analysis. The hydrologic variables at each computational grid, that is, precipitation, ET, runoff, and soil moisture during the 5 categories, are arithmetically averaged and compared to the 60-year mean with Student's $t$-test. Table 4 summarizes the percentage change of the hydrologic variables in the eight watersheds as well as major croplands for all the categories except the category of $-0.34 \sim 0.34$ in which the changes of hydrological variables are insignificant.

Figures 4 and 5 further show the fluctuation percentages of the hydrologic variables when EASMI standardized anomalies are above 1.00 and below -1.00 , respectively. Fluctuation percentage (\%) of a variable is calculated as follows:

$$
\mathrm{FP}=100 * \frac{(e-\bar{e})}{\bar{e}}
$$

where FP is the fluctuation percentage of a variable; $e$ denotes the variable; and $\bar{e}$ is the mean of variable during the period of 1952-2011. Student's $t$-test is applied in Figures 4 and 5 to examine if $e$ is significantly or insignificantly different from $\bar{e}$ (with the significance level of 0.05 ). The two categories are selected herein since several recent studies have reported that climatic extremes are likely to become more severe in future due to climate change [64]. Besides, their sampling sizes (i.e., 
TABLE 4: Calculated anomalies of hydrological variables (\%) under various monsoon scenarios.

\begin{tabular}{lcccccccccccccccc}
\hline \multirow{2}{*}{ Area } & \multicolumn{4}{c}{ EASMI $(0.34 \sim 1.00)$} & \multicolumn{4}{c}{ EASMI $(1.00 \sim 2.00)$} & \multicolumn{3}{c}{ EASMI $(-2.00 \sim-1.00)$} & \multicolumn{3}{c}{ EASMI (-1.00 -0.34) } \\
& SM & $R$ & ET & $P$ & SM & $R$ & ET & $P$ & SM & $R$ & ET & $P$ & SM & $R$ & ET & $P$ \\
\hline YRB & -1.0 & -11.5 & -7.1 & -8.2 & 3.1 & 18.6 & 6.8 & 8.6 & -2.3 & -16.8 & -4.8 & -9.3 & -0.4 & 1.2 & 0.2 & 0.9 \\
YZB & -0.5 & -5.3 & -2.3 & -3.5 & 3.1 & 7.0 & 3.5 & 3.0 & 0.2 & 1.6 & -0.5 & 1.6 & -1.2 & -1.0 & -0.9 & -0.6 \\
LRB & -1.7 & -13.4 & -3.0 & -6.7 & 4.1 & 32.1 & 10.7 & 16.7 & -1.2 & -11.0 & -4.3 & -5.3 & -1.1 & -6.9 & -3.0 & -4.8 \\
PRB & 0.9 & -5.0 & -0.2 & -2.1 & 0.2 & -0.0 & 2.1 & 0.5 & 0.8 & 5.0 & -0.4 & 3.0 & -0.1 & -0.2 & -0.6 & -0.4 \\
HRB & -0.7 & -12.7 & -0.8 & -7.1 & 5.4 & 17.4 & 5.6 & 9.1 & 0.1 & 2.0 & -2.0 & -4.1 & -2.5 & 0.1 & -1.9 & 1.1 \\
HHB & -0.7 & -12.9 & -4.8 & -5.8 & 9.1 & 49.0 & 11.4 & 18.5 & -5.0 & -26.7 & -7.2 & -14.0 & -2.9 & -9.5 & -2.3 & -3.8 \\
SRB & -0.2 & -3.4 & 0.8 & -0.6 & 1.8 & 9.0 & 5.3 & 7.0 & -1.4 & -8.2 & -5.7 & -7.5 & -1.1 & -3.1 & -1.6 & -1.4 \\
SEB & 2.7 & 10.6 & 2.0 & 9.4 & 3.1 & 4.7 & 1.3 & -0.4 & -3.4 & -7.2 & -0.7 & -2.3 & -1.4 & 2.3 & -0.5 & 0.9 \\
CDP & 2.7 & 9.5 & 3.1 & 7.0 & 5.0 & 13.3 & 9.1 & 11.4 & -2.4 & -7.9 & -4.8 & -7.8 & -2.2 & -7.1 & -2.7 & -4.6 \\
SJP & 1.1 & 9.0 & 3.0 & 5.3 & 3.3 & 19.0 & 7.3 & 11.3 & -1.7 & -13.9 & -4.9 & -10.7 & -2.2 & -8.6 & -3.6 & -4.4 \\
NCP & -1.4 & -14.1 & -3.2 & -7.4 & 7.0 & 32.9 & 8.2 & 13.0 & -2.0 & -13.8 & -4.8 & -10.2 & -2.6 & -4.3 & -2.1 & -0.9 \\
\hline
\end{tabular}

Note: YRB: Yellow River Basin; YZB: Yangtze River Basin; LRB: Liaohe River Basin; PRB: Pearl River Basin; HRB: Huaihe River Basin; HHB: Haihe Basin; SRB: Songhua River Basin; SEB: Southeast Rivers Basin; CDP: Chengdu Plain; SJP: Sanjiang Plain; NCP: North China Plain.

$n=10$ and 9, resp.) satisfy the requirement of Student's $t$-test [63]. Therefore, the following discussion will focus on the two extreme categories of EASMI.

5.2.1. When EASMI Standardized Anomaly Is above 1.00. Figure 4 indicates that the runoff increases significantly over northern China, especially in the suburb of Beijing and Hebei province where shortage of water resources is the severest in China [65]. Figure 4 presents a 50\% 105\% increment of runoff in the suburb of Beijing and Hebei province when the EASMI standardized anomaly is above 1.00. In contrast, no obvious change of runoff is observed in the southern China, where the fluctuation is generally in the range of $-10 \% \sim 10 \%$. Comparing to the variation of runoff, both the precipitation and ET in East China vary in-phase and have the similar spatial pattern, but only with about a half fluctuating rate. Similar to runoff, the areas with the most increments of precipitation and ET are located in the Haihe and Liaohe River Basins. The precipitation and ET in the basins of Liaohe and Haihe increase by about $17 \sim 18 \%$ and $11 \%$ when the EASMI standardized anomaly is above 1.00 , respectively. Based on Figure 4, runoff is more sensitive to the change of EASMI than precipitation or ET does; therefore runoff could serve as an effective index to climate change in the northern China, especially in the Haihe River Basin.

Comparing to other hydrologic variables, soil moisture usually shows a lag and damping response to the fluctuation of EASM. Figure 4 indicates that the soil moisture in Haihe basin varies significantly with 5 10\% increment (10 20.9\% in the suburb of Beijing), when the EASMI standardized anomaly is above 1.00 . Besides, different from precipitation and runoff, there is much more area in the South China with notable increment in soil moisture (Student's $t$-test shows above $95 \%$ of confidence level). Based on the study, there is no evidence for severe soil moisture droughts in the South China during strong EASM years. It is different from the drought analysis based on the precipitation indices $[6,66]$, suggesting that agricultural drought and meteorological drought may respond differently to monsoon.
5.2.2. When EASMI Standardized Anomaly Is below -1.00. The Figure 5 shows that the most runoff decrement (with a calculated 30\% dropping) occurs in the southern regions of the Haihe River Basin as well as some areas of the middle Yellow river, although it does not exceed the 95\% confidence level of Student's $t$-test. Other hydrologic variables indicate the similar spatial variation patterns in the area, although the variations are gentle compared to the runoff. Figure 5 further indicates that all the hydrologic variables in the middle and lower Yangtze River Basin significantly increase when EASMI standardized anomaly is below -1.00. As discussed before, the hydrologic variables respond oppositely to EASM fluctuation in the upper Yangtze River Basin, which results in an inconspicuous change of the average hydrologic variables throughout the entire basin, as shown in Table 4. The biggest increment of runoff occurs in the lower Yangtze River, which reaches $30 \sim 50 \%$ increase. The spatial pattern of rainfall change is similar to runoff except the fluctuation rates are much smaller and the peak increment of rainfall occurs a bit upstream.

It is interesting that both ET and soil moisture significantly increase (5 10\%) in the mountain area to the southeast of Chongqing City of Sichuan province when EASMI standardized anomaly is below -1.00 , whereas the peak increase of rainfall occurs in the faraway downstream. The lack of synchronization between soil moisture and precipitation or runoff might be due to the hysteretic nature of cumulative soil moisture. Soil moisture usually shows a lag and damping response to climate change [35].

The FP of hydrologic variables in other categories of EASM fluctuation, that is, $0.34 \sim 1.00$ and $-1.00 \sim-0.34$ in the eight watersheds, is summarized in Table 4. Based on Table 4, the Liaohe and Haihe are the most sensitive basins responding to EASMI increase. The hydrologic variables in the two basins vary dramatically as the EASMI standardized anomaly is above 1.00; for example, the runoffs increase by $32 \%$ and $49 \%$ in the basins of Liaohe and Haihe, respectively. In contrast, the basins of Haihe and Yellow River are ranked the top 2 whose hydrologic variables are the most sensitive 


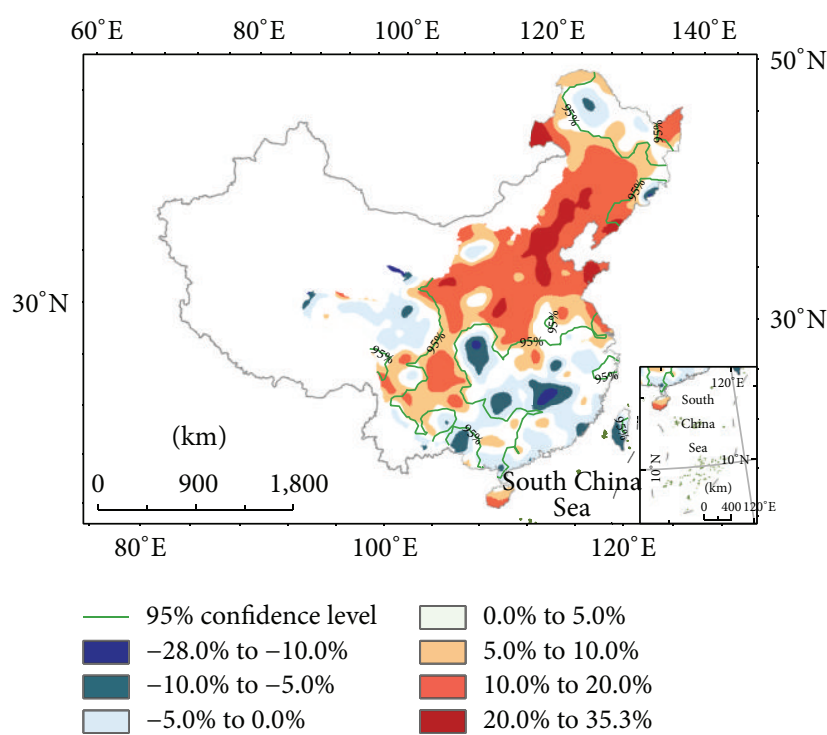

(a)

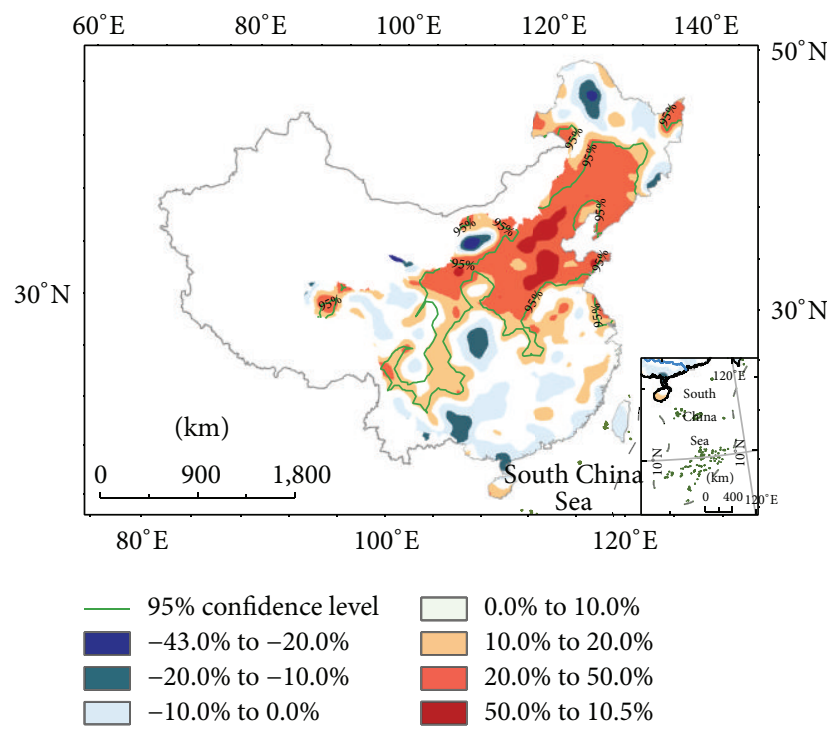

(c)

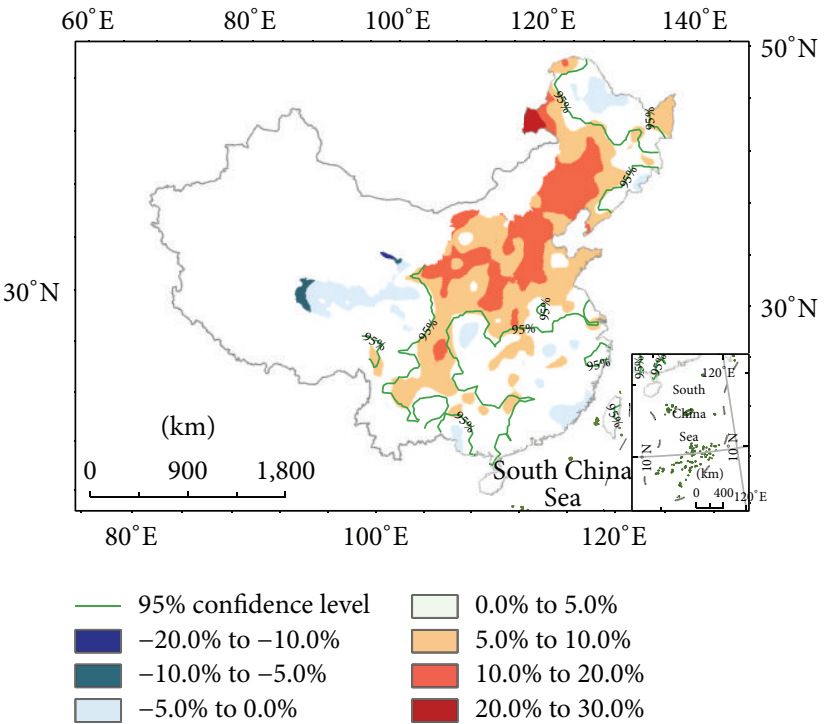

(b)

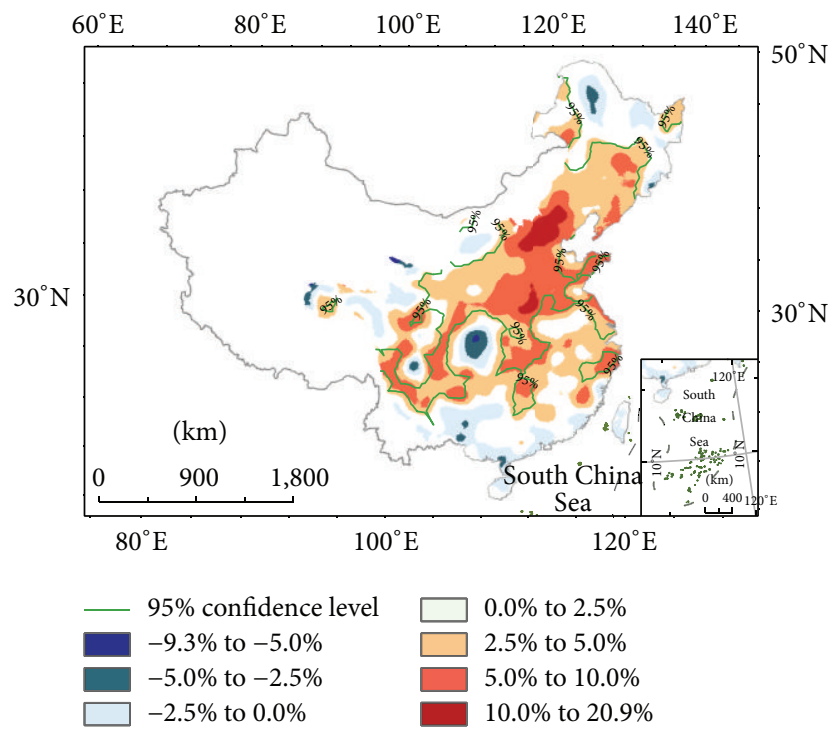

(d)

FIGURE 4: Variation of precipitation (a), ET (b), runoff (c), and soil moisture (d) when EASMI standardized anomaly is within 1.00 2.00. The colors present the percentages of variation of variables from their annual means. The green curves draw the outline of regions with $95 \%$ confidence level in Student's $t$-test.

to when EASMI standardized anomaly is below -1.00 , which brings severe drought to these regions. The runoffs in the watersheds of Haihe and Yellow River decrease by about 27\% and $17 \%$.

\subsection{Sensitivity of Hydrologic Variables to EASM Fluctuation in} Croplands. Besides the FP of hydrologic variables to EASM fluctuation in the eight watersheds, Table 4 also shows their FP in three main croplands of China, that is, plains of Chengdu Plain (CDP), Sanjiang Plain (SJP), and North China Plain (NCP). Figure 1 shows the locations of ten croplands, that is, Sanjiang, Songnen, Hetao, North China (including Jianghuai), Taihu, Jianghan, Dongtinghu, Poyanghu, and Chengdu. Since available water resources such as runoff and soil moisture mainly restrict the grain production of croplands in the north and west; Table 4 selects the three main croplands as examples and summarizes the variations of their hydrologic variables with EASM. The Chengdu and Sanjiang Plains represent the government commodity grain bases in the west and north, respectively. North China Plain is the largest alluvial plain of eastern Asia and main area of sorghum, millet, maize, and cotton production in China. Wheat, sesame seed, and peanuts are also grown here.

Figure 3(a) indicates the runoffs in the three croplands are positively and highly correlated to EASM in general, although Table 4 suggests an exceptional case; that is, antiphase variations of hydrologic variables are observed in the North China Plain when the EASMI standardized anomaly is in 


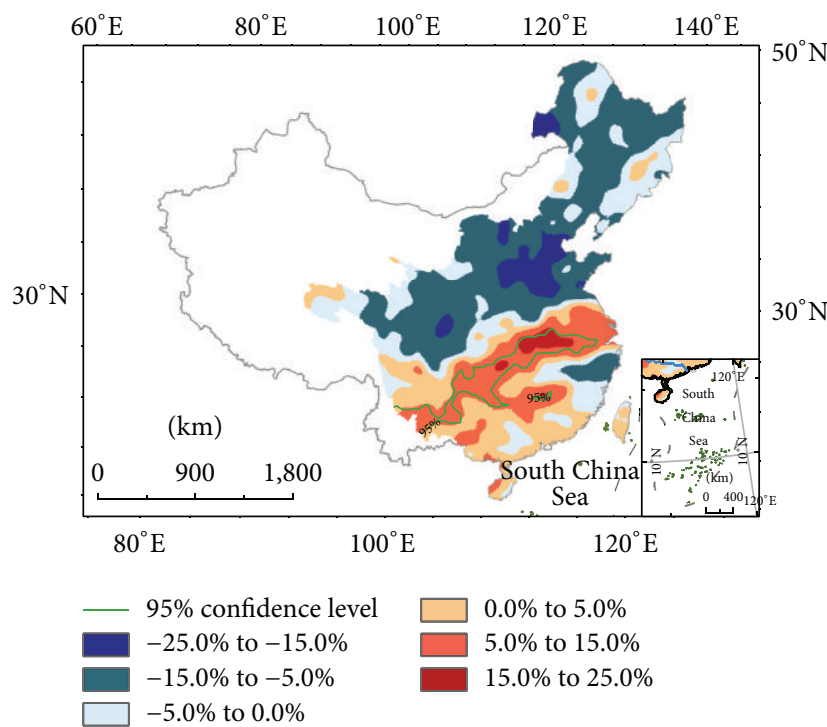

(a)

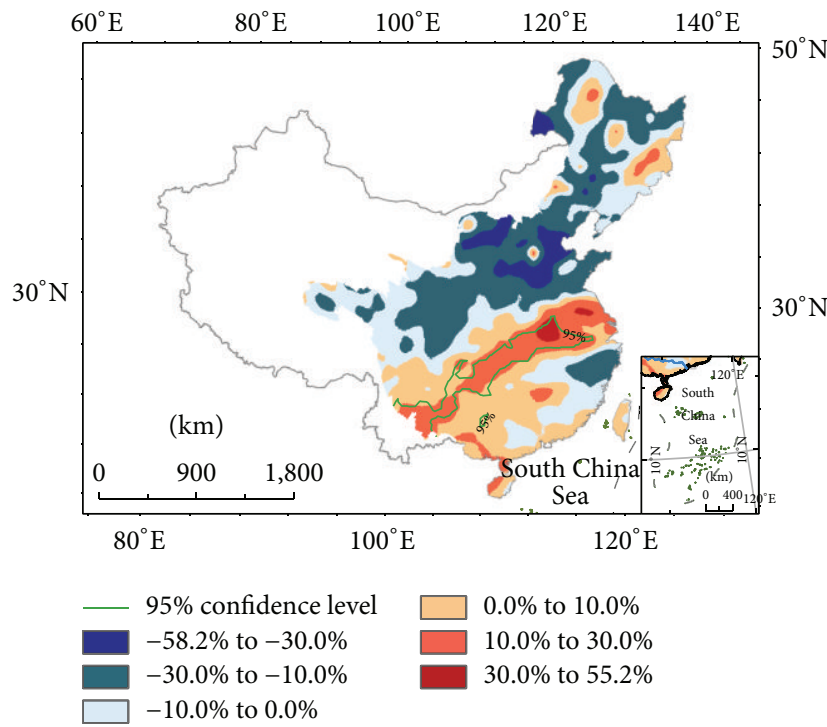

(c)

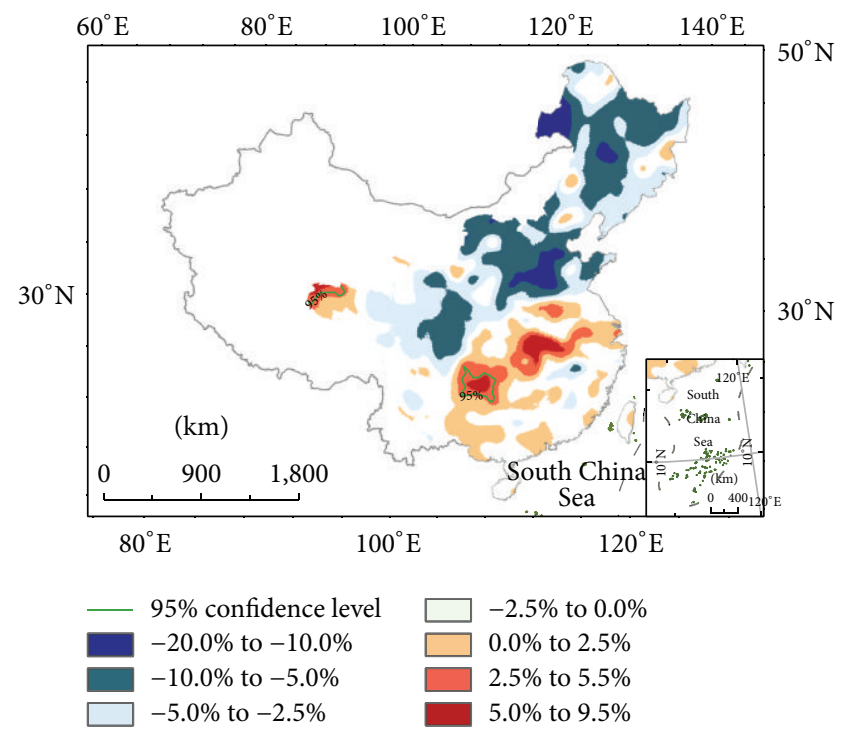

(b)

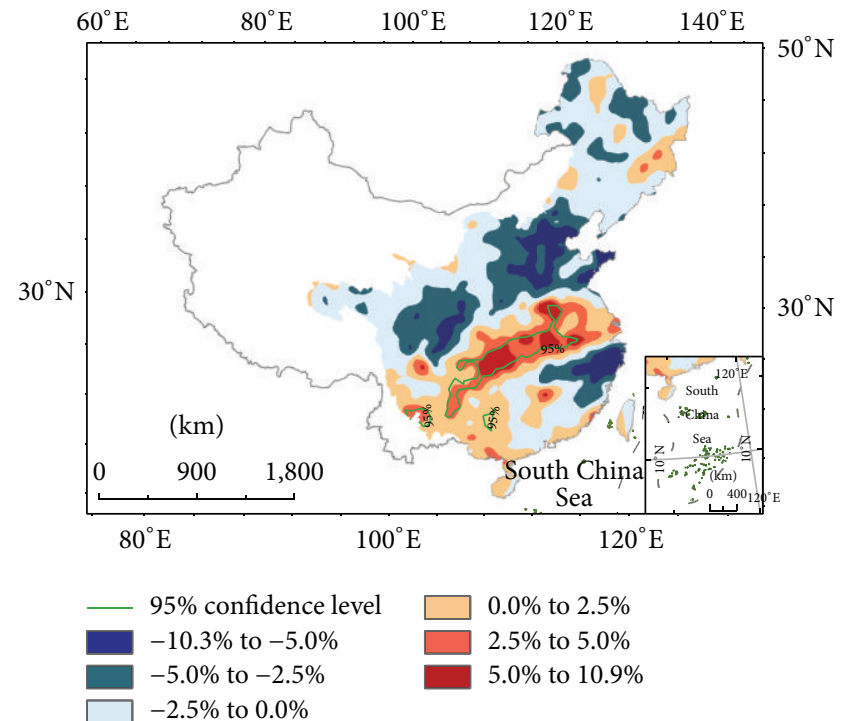

(d)

FIGURE 5: Variation of precipitation (a), ET (b), runoff (c), and soil moisture (d) when EASMI standardized anomaly is within -2.00 -1.00. The colors present the percentages of variation of variables from their annual means. The green curves draw the outline of regions with $95 \%$ confidence level in Student's $t$-test.

the category of $0.34 \sim 1.00$. The abnormal example might be induced by the interannual relation between EASM and hydrological variable which is more complex than their interdecadal relation. The category of $0.34 \sim 1.00$ includes the years 1952, 1965, 1966, 1972, 1973, and 1975. Among them, El Niño, the most outstanding interannual variability in the ocean, has occurred in the years of 1965, 1966, 1972, and 1973. In the El Niño developing summers, warm Sea Surface Temperature (SST) anomalies could enhance convection in the tropical central Pacific and trigger an anomalous cyclone in the lower troposphere over the western North Pacific via the Gill-Matsuno mechanism [67, 68], which in turn causes the anomalous rainfall in China [69]. During El Niño mature phase, the negative precipitation anomalies in the north China are statistically significant [70].

\section{Conclusions and Discussions}

This study identifies the watershed and crop regions in East China where hydrologic variables, that is, rainfall precipitation, ET, runoff, and soil moisture, are significantly correlated to EASM fluctuation. The MK nonparametric analyses indicate that the most significant positive correlation between runoff and EASM is located in the North China Plain and middle-lower Yellow River watershed, while the most 
significant negative correlation exists in the upper reach of Pear River.

This study also examines the sensitivity of the hydrologic variables to the fluctuation of EASMI. Spatial analyses indicate the watersheds of Liaohe, Haihe, and the middle and lower Yellow River are the most sensitive regions susceptible to hydrological change when EASMI standardized anomaly is above 1.00. In contrast, the runoffs in the watersheds of Haihe and Yellow River decrease the most significantly when EASMI standardized anomaly is below -1.00 , leading to severe droughts in the regions. Since runoff is double sensitive to the EASM fluctuation compared to precipitation over East China, it might serve as an efficient index to reflect the future droughts and floods due to climate change in the region.

This study also suffers from several shortcomings. First of all, the variation of the hydrologic variables in terms of the fluctuation ranges of EASMI is quantified based on limited historical data. The VIC hydrologic models need to be calibrated and verified by flow records at gauge stations (unimpaired to natural discharge) in major rivers and most of them are built after the year of 1949. More robust conclusions are expected in future after more data are collected. Secondly, implicit stationarity hypothesis has been applied in the study that assumes the change of climate, land cover, or other anthropogenic influences have not altered the main characterizes of hydrologic variables, for example, frequency. Recent studies have evidenced many flood series exhibit a nonstationarity, which challenges the conventional assumption in prediction [71]. To consider the nonstationary influence, a statistic of time-varying approach could be applied in the future study.

\section{Competing Interests}

The authors declare that they have no competing interests.

\section{Acknowledgments}

The financial support from the National Major Basic Research Program of China (2010CB428404) and the "Hundred Talents Program" of Chinese Academy of Sciences is gratefully acknowledged.

\section{References}

[1] L. Sun, B. Shen, Z. Gao et al., "The impacts of moisture transport of East Asian monsoon on summer precipitation in Northeast China," Advances in Atmospheric Sciences, vol. 24, no. 4, pp. 606-618, 2007.

[2] Z. H. Jiang, S. Yang, J. H. He, J. Li, and J. Liang, "Interdecadal variations of East Asian summer monsoon northward propagation and influences on summer precipitation over East China," Meteorology and Atmospheric Physics, vol. 100, no. 1-4, pp. 101119, 2008.

[3] X. Zhou, L. Sun, W. Huang, W. Cheng, and N. Jia, "Precipitation in the Yellow River drainage basin and East Asian monsoon strength on a decadal time scale," Quaternary Research, vol. 78, no. 3, pp. 486-491, 2012.
[4] F. Chen, Y.-J. Yuan, W.-S. Wei et al., "Reconstructed precipitation for the north-central China over the past 380 years and its linkages to East Asian summer monsoon variability," Quaternary International, vol. 283, pp. 36-45, 2013.

[5] M. Shi and Q. Zhu, "An abrupt change in the intensity of the East Asian summer monsoon index and its relationship with temperature and precipitation over East China," International Journal of Climatology, vol. 16, no. 7, pp. 757-764, 1996.

[6] J. Zhu, S. Wang, and Q. Mu, "80a-oscillation of summer rainfall over the east part of China and East Asian summer monsoon," Advances in Atmospheric Science, vol. 18, no. 5, pp. 1043-1051, 2001.

[7] W. Qian, H.-S. Kang, and D.-K. Lee, "Distribution of seasonal rainfall in the East Asian monsoon region," Theoretical and Applied Climatology, vol. 73, no. 3-4, pp. 151-168, 2002.

[8] X. Sun, L. Chen, and J. He, "Index of land-sea thermal difference and its relation to interannual variation of summer circulation and rainfall over east Asian," Acta Meteorological Sinica, vol. 60, no. 2, pp. 164-172, 2002 (Chinese).

[9] J. M. Lu, J. Z. Ren, and J. H. Ju, “The inter-decadal variability of East Asia monsoon and its effect on the rainfall over China," Journal of Tropical Meteorology, vol. 10, no. 1, pp. 14-22, 2004.

[10] X. F. Liu and J. Wang, "The east Asian subtropical summer monsoon index and its relation with climate anomalies in China," Journal of Tropical Meteorology, vol. 22, no. 6, pp. 533538, 2006 (Chinese).

[11] S. Yu, X. Shi, and X. Lin, "Interannual variation of East Asian summer monsoon and its impacts on general circulation and precipitation," Journal of Geographical Sciences, vol. 19, no. 1, pp. 67-80, 2009.

[12] Y. Ding, Z. Wang, and Y. Sun, "Inter-decadal variation of the summer precipitation in East China and its association with decreasing Asian summer monsoon. Part I: observed evidences," International Journal of Climatology, vol. 28, no. 9, pp. 1139-1161, 2008.

[13] Y. Ding, Y. Sun, Z. Wang, Y. Zhu, and Y. Song, "Interdecadal variation of the summer precipitation in China and its association with decreasing Asian summer monsoon Part II: possible causes," International Journal of Climatology, vol. 29, no. 13, pp. 1926-1944, 2009.

[14] Y. Sun and Y. H. Ding, "Responses of South and East Asian summer monsoons to different land-sea temperature increases under a warming scenario," Chinese Science Bulletin, vol. 56, no. 25, pp. 2718-2726, 2011.

[15] B. Z. Ge, Z. F. Wang, X. B. Xu et al., "Impact of the East Asian summer monsoon on long-term variations in the acidity of summer precipitation in Central China," Atmospheric Chemistry and Physics, vol. 11, no. 4, pp. 1671-1684, 2011.

[16] C. Zhu, X. Zhou, P. Zhao, L. Chen, and J. He, "Onset of East Asian subtropical summer monsoon and rainy season in China," Science China Earth Sciences, vol. 54, no. 12, pp. 18451853, 2011.

[17] D. Si and Y. Ding, "The tropospheric biennial oscillation in the East Asian monsoon region and its influence on the precipitation in China and large-scale atmospheric circulation in East Asia," International Journal of Climatology, vol. 32, no. 11, pp. 1697-1716, 2012.

[18] H. Chen and F. Xue, "Numerical simulation of the decadal variations in the East Asian summer monsoon and summer rainfall in eastern China," Chinese Journal of Atmospheric Sciences, vol. 37, no. 5, pp. 1143-1153, 2013 (Chinese). 
[19] H. Yang, X. Zhi, J. Gao, and Y. Liu, "Variation of East Asian summer monsoon and its relationship with precipitation of China in recent 111 years," Agricultural Science \& Technology, vol. 12, no. 11, pp. 1711-1716, 2011.

[20] R. Huang, J. Chen, and G. Huang, "Characteristics and variations of the East Asian monsoon system and its impacts on climate disasters in China," Advances in Atmospheric Sciences, vol. 24, no. 6, pp. 993-1023, 2007.

[21] Q. Y. Guo, J. N. Cai, X. M. Shao, and W. Y. Sha, "Studies on the variations of East Asian summer monsoon during AD 18732000," Journal of the Atmospheric Sciences, vol. 28, no. 2, pp. 206-215, 2004 (Chinese).

[22] P. Zhao and Z. Zhou, "An East Asian subtropical summer monsoon index and its relationship to summer rainfall in China," Acta Meteorologica Sinica, vol. 23, no. 1, pp. 18-28, 2009.

[23] X. Lin, C. Zhu, and J. Lü, "Decadal change of the East Asian summer monsoon and its related surface temperature in AsiaPacific during 1880-2004," Chinese Science Bulletin, vol. 58, no. 35, pp. 4497-4503, 2013.

[24] W. Li, L. Li, M. Ting, and Y. Liu, "Intensification of Northern Hemisphere subtropical highs in a warming climate," Nature Geoscience, vol. 5, pp. 830-834, 2012.

[25] B. Yang and M. Tan, "Variability of the East Asian summer monsoon and its relationship with regional temperature and moisture change during the last millennium," Quaternary Sciences, vol. 29, pp. 880-887, 2009.

[26] Q. Zhang, C.-Y. Xu, T. Jiang, and Y. Wu, "Possible influence of ENSO on annual maximum streamflow of the Yangtze River, China," Journal of Hydrology, vol. 333, no. 2-4, pp. 265-274, 2007.

[27] J. Xu and Y. Ma, "Response of the hydrological regime of the Yellow River to the changing monsoon intensity and human activity," Hydrological Sciences Journal, vol. 54, no. 1, pp. 90-100, 2009.

[28] J. Xu, “Temporal variation in summer monsoon intensity since 1873 and its influence on runoff in the drainage area between Hekouzhen and Longmen, Yellow River basin, China," Climatic Change, vol. 112, no. 2, pp. 283-298, 2012.

[29] W. Wei, Y. Chang, and Z. Dai, "Streamflow changes of the Changjiang (Yangtze) River in the recent 60 years: impacts of the East Asian summer monsoon, ENSO, and human activities," Quaternary International, vol. 336, pp. 98-107, 2014.

[30] W. Korres, T. G. Reichenau, and K. Schneider, "Patterns and scaling properties of surface soil moisture in an agricultural landscape: an ecohydrological modeling study," Journal of Hydrology, vol. 498, pp. 89-102, 2013.

[31] Z. Y. Zuo and R. H. Zhang, "The spring soil moisture and the summer rainfall in eastern China," Chinese Science Bulletin, vol. 52, no. 23, pp. 3310-3312, 2007.

[32] X. Jun and Y. D. Chen, "Water problems and opportunities in the hydrological sciences in China," Hydrological Sciences Journal, vol. 46, no. 6, pp. 907-921, 2001.

[33] X.-J. Zhang, Q. Tang, M. Pan, and Y. Tang, "A long-term land surface hydrologic fluxes and states dataset for China," Journal of Hydrometeorology, vol. 15, no. 5, pp. 2067-2084, 2014.

[34] C. Tang and T. C. Piechota, "Spatial and temporal soil moisture and drought variability in the Upper Colorado River Basin," Journal of Hydrology, vol. 379, no. 1-2, pp. 122-135, 2009.

[35] C. Tang, T. C. Piechota, and D. Chen, "Relationships between oceanic-atmospheric patterns and soil moisture in the Upper Colorado River Basin," Journal of Hydrology, vol. 411, no. 1-2, pp. 77-90, 2011.
[36] C. Tang, B. T. Crosby, J. M. Wheaton, and T. C. Piechota, "Assessing streamflow sensitivity to temperature increases in the Salmon River Basin, Idaho," Global and Planetary Change, vol. 88-89, pp. 32-44, 2012.

[37] FAO, Digital Soil Map of the World and Derived Soil Properties, vol. 1 of Land and Water Digital Media Series: CD-ROM, Food and Agriculture Organization, 1998.

[38] E. P. Maurer, A. W. Wood, J. C. Adam, D. P. Lettenmaier, and B. Nijssen, "A long-term hydrologically based dataset of land surface fluxes and states for the conterminous United States," Journal of Climate, vol. 15, no. 22, pp. 3237-3251, 2002.

[39] M. C. Hansen, R. S. Defries, J. R. G. Townshend, and R. Sohlberg, "Global land cover classification at $1 \mathrm{~km}$ spatial resolution using a classification tree approach," International Journal of Remote Sensing, vol. 21, no. 6-7, pp. 1331-1364, 2000.

[40] J. He and K. Yang, China Meteorological Forcing Dataset, Cold and Arid Regions Science Data Center, Lanzhou, China, 2011.

[41] M. Pan, A. K. Sahoo, T. J. Troy, R. K. Vinukollu, J. Sheffield, and A. E. F. Wood, "Multisource estimation of long-term terrestrial water budget for major global river basins," Journal of Climate, vol. 25, no. 9, pp. 3191-3206, 2012.

[42] M. Brodzik and R. Armstrong, Northern Hemisphere EASEGrid 2.0 Weekly Snow Cover and Sea Ice Extent, Version 4: Snow Frequency 1966-2010, National Snow and Ice Data Center, Boulder, Colo, USA, 2013, http://nsidc.org/data/docs/daac/nsidc0046_nh_ease_snow_seaice.gd.html.

[43] Q. Y. Guo and D. K. Zuo, "A study of climate related with Eastern Monsoon," in Progress in Geography, pp. 63-70, Science Press, Beijing, China, 1990 (Chinese).

[44] N. Shi, J. J. Lu, and Q. G. Zhu, "Intensity Index of winter and summer Eastern Asian monsoon and the relative climate change," Journal of Nanjing Institute of Meteorology, vol. 19, no. 2, pp. 168-177, 1996 (Chinese).

[45] J. J. Xu, Q. G. Zhu, and N. Shi, "An analysis of abnormal spectrum in the variation of summer eastern Asian monsoon in the past 100 years," Journal of Meteorology, vol. 55, no. 5, pp. 620-626, 1997.

[46] F. F. Zhao, Z. X. Xu, J. X. Huang, and J. Y. Li, "Monotonic trend and abrupt changes for major climate variables in the headwater catchment of the Yellow River basin," Hydrological Processes, vol. 22, no. 23, pp. 4587-4599, 2008.

[47] P. Zhao, J. M. Chen, D. Xiao, S. L. Nan, Y. Zou, and B. T. Zhou, "Summer Asian-Pacific oscillation and its relationship with atmospheric circulation and monsoon rainfall," Acta Meteorologica Sinica, vol. 22, no. 4, pp. 455-471, 2008.

[48] H. B. Mann, "Nonparametric tests against trend," Econometrica, vol. 13, no. 3, pp. 245-259, 1945.

[49] M. G. Kendall, Rank Correlation Methods, C. Griffin, 1948.

[50] R. M. Hirsch, J. R. Slack, and R. A. Smith, "Techniques of trend analysis for monthly water quality data," Water Resources Research, vol. 18, no. 1, pp. 107-121, 1982.

[51] H. T. Mitosek, "Climate variability and change within the discharge time series: a statistical approach," Climatic Change, vol. 29, no. 1, pp. 101-116, 1995.

[52] S. Yue, P. Pilon, B. Phinney, and G. Cavadias, "The influence of autocorrelation on the ability to detect trend in hydrological series," Hydrological Processes, vol. 16, no. 9, pp. 1807-1829, 2002.

[53] S. Yue and C. Wang, "The Mann-Kendall test modified by effective sample size to detect trend in serially correlated hydrological series," Water Resources Management, vol. 18, no. 3, pp. 201-218, 2004. 
[54] L. Seo, T.-W. Kim, and H.-H. Kwon, "Investigation of trend variations in annual maximum rainfalls in South Korea," KSCE Journal of Civil Engineering, vol. 16, no. 2, pp. 215-221, 2012.

[55] R. M. Hirsch and J. R. Slack, "A nonparametric trend test for seasonal data with serial dependence," Water Resources Research, vol. 20, no. 6, pp. 727-732, 1984.

[56] D. Helsel and R. M. Hirsch, Statistical Methods in Water Resources: US Geological Survey Techniques of Water Resources Investigations, book 4, chapter A3, United States Geological Survey, Virginia, Va, USA, 2002.

[57] R. Zhang, A. Sumi, and M. Kimoto, "Impact of El Niño on the East Asian monsoon: a diagnostic study of the '86/87 and '91/92 events," Journal of the Meteorological Society of Japan, vol. 74, no. 1, pp. 49-62, 1996.

[58] F. Xue and C. Liu, "The influence of moderate ENSO on summer rainfall in eastern China and its comparison with strong ENSO," Chinese Science Bulletin, vol. 53, no. 5, pp. 791-800, 2008.

[59] J. Mao, J. C. L. Chan, and G. Wu, "Interannual variations of early summer monsoon rainfall over South China under different PDO backgrounds," International Journal of Climatology, vol. 31, no. 6, pp. 847-862, 2011.

[60] L. Yu, T. Furevik, O. H. Otterå, and Y. Gao, "Modulation of the Pacific Decadal Oscillation on the summer precipitation over East China: a comparison of observations to 600-years control run of Bergen Climate Model," Climate Dynamics, vol. 44, no. 1-2, pp. 475-494, 2014.

[61] S. Kumar, V. Merwade, J. Kam, and K. Thurner, "Streamflow trends in Indiana: effects of long term persistence, precipitation and subsurface drains," Journal of Hydrology, vol. 374, no. 1-2, pp. 171-183, 2009.

[62] Student, “The probable error of a mean," Biometrika, vol. 6, no. 1, pp. 1-25, 1908.

[63] J. C. F. de Winter, "Using the Student's t-test with extremely small sample sizes," Practical Assessment, Research \& Evaluation, vol. 18, no. 10, pp. 1-12, 2013.

[64] Y. Hirabayashi, S. Kanae, S. Emori, T. Oki, and M. Kimoto, "Global projections of changing risks of floods and droughts in a changing climate," Hydrological Sciences Journal, vol. 53, no. 4, pp. 754-772, 2008.

[65] D. Jiang, K. Wang, Z. Li, and Q. Wang, "Variability of extreme summer precipitation over Circum-Bohai-Sea region during 1961-2008," Theoretical and Applied Climatology, vol. 104, no. 34, pp. 501-509, 2011.

[66] Q. Guo, J. Cai, X. Shao, and W. Sha, "Interdecadal variability of East-Asian summer monsoon and its impact on the climate of China," Acta Geographica Sinica, vol. 58, no. 4, pp. 576-582, 2003 (Chinese).

[67] A. E. Gill, "Some simple solutions for heat-induced tropical circulation," Quarterly Journal of the Royal Meteorological Society, vol. 106, no. 449, pp. 447-462, 1980.

[68] T. Matsuno, "Quasi-geostrophic motions in the equatorial area," Journal of the Meteorological Society of Japan, vol. 44, no. 1, pp. 25-43, 1966.

[69] R. Wu, Z.-Z. Hu, and B. P. Kirtman, "Evolution of ENSO-related rainfall anomalies in East Asia," Journal of Climate, vol. 16, no. 22, pp. 3742-3758, 2003.

[70] X. G. Zhang and H. G. Zhao, "The El Nino event in 1986-1987 and its impact on summer lain belt and temperature in China," Meteorological Monthly, vol. 14, no. 4, pp. 3-7, 1988.

[71] L. Xiong, T. Du, C.-Y. Xu, S. Guo, C. Jiang, and C. J. Gippel, "Non-stationary annual maximum flood frequency analysis using the norming constants method to consider nonstationarity in the annual daily flow series," Water Resources Management, vol. 29, no. 10, pp. 3615-3633, 2015. 

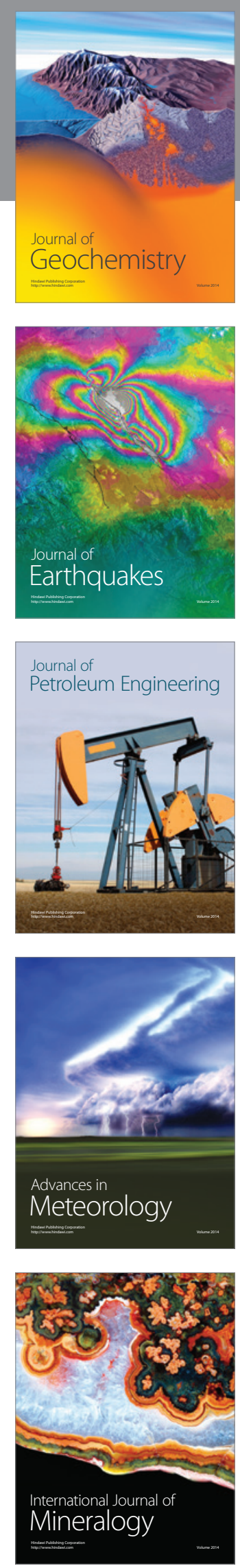
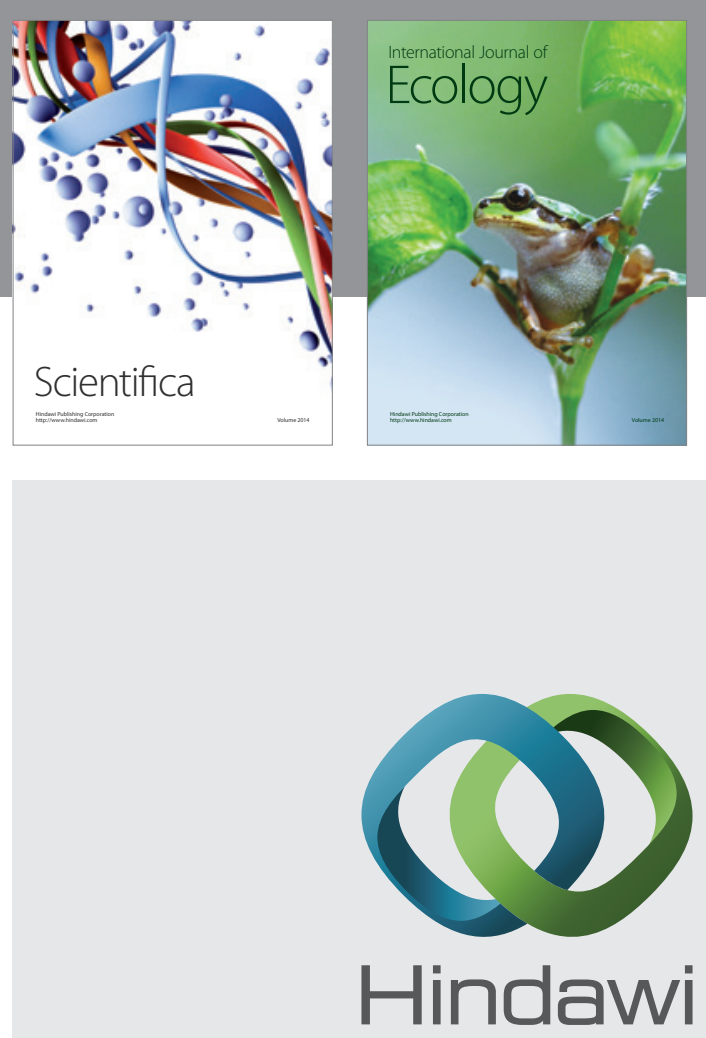

Submit your manuscripts at

http://www.hindawi.com
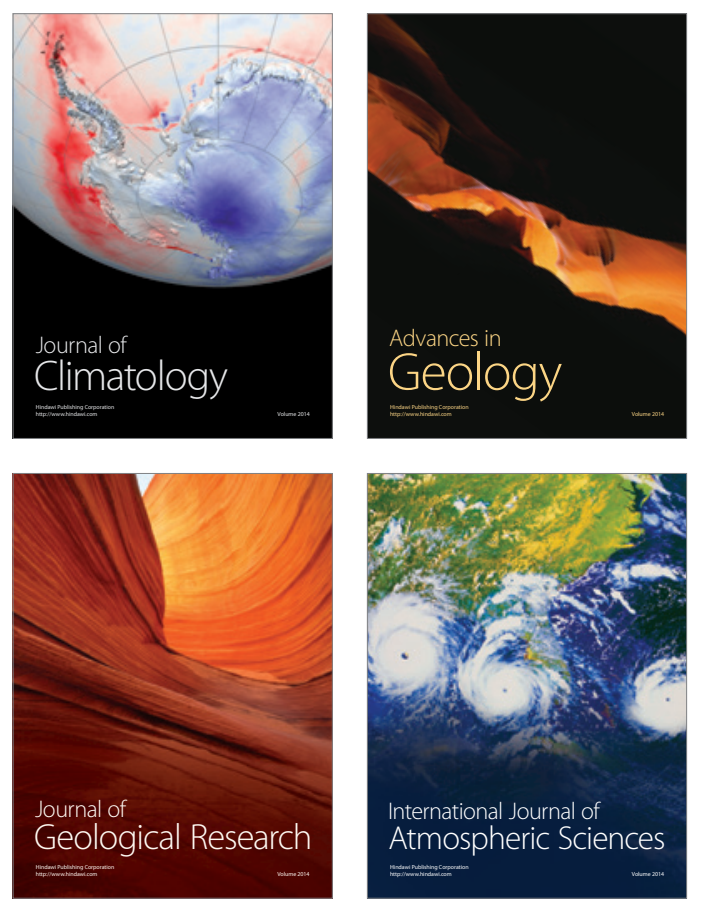

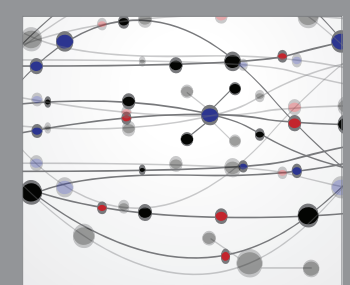

The Scientific

\section{World Journal}
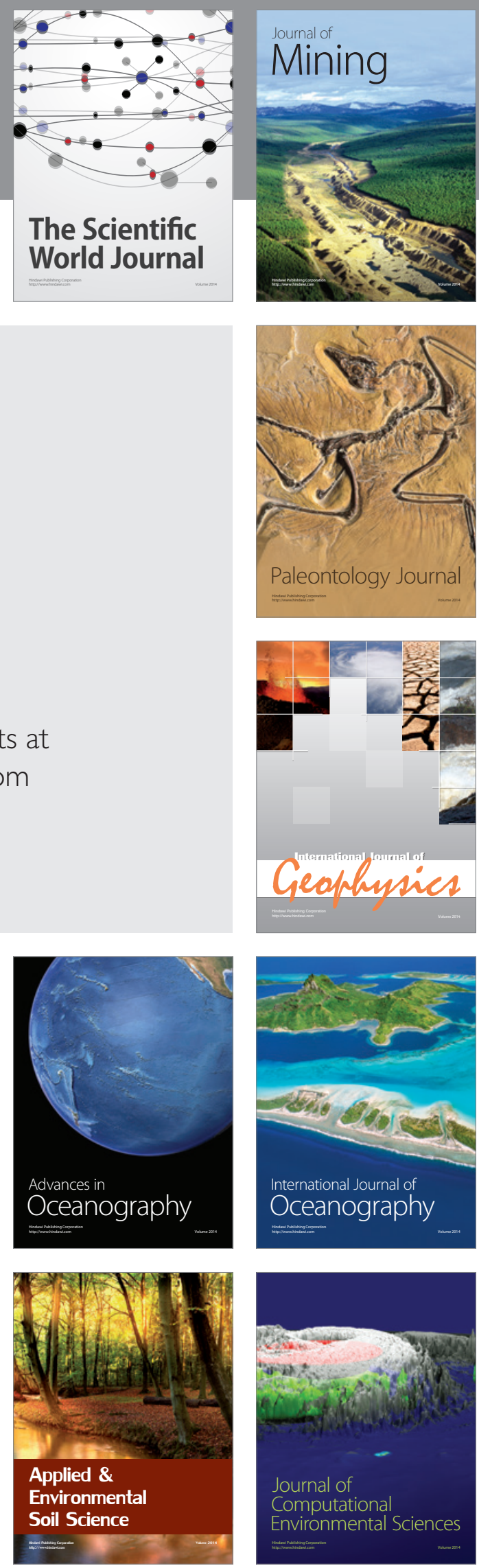